\title{
Imagens Contraditórias e Fragmentadas: sobre o Lugar dos índios nos Livros Didáticos*
}

\author{
Luis Donisete Benzi Grupioni \\ Universidade de São Paulo (USP)
}

\section{Introdução}

Entre várias conclusões algumas surpreendentes, outras estarrecedoras - apresentadas, em março de 1994, pelo grupo de trabalho instituído pelo Ministério da Educação e do Desporto ${ }^{1}$ para analisar os livros didáticos mais solicitados pelos professores das primeiras séries escolares, uma chamou-me especialmente a atenção. ${ }^{2}$ Ao analisar as indicações constantes em 60 livros didáticos de Estudos Sociais, de $1^{\mathrm{a}}$ a $4^{\mathrm{a}}$ série, para as comemorações cívicas na escola, ao longo do ano letivo, os avaliadores encontraram 957 citações, distribuídas em 39 datas diferentes. O Dia do índio, 19 de abril, foi citado em 51 dos 60 livros analisados, ocupando um lugar de destaque no calendário cívico proposto nesses livros didáticos. Diante deste dado, caberia perguntarmos: qual a imagem do

'Comunicação apresentada no grupo de trabalho "Textos Didáticos em Sala de Aula", no $2^{\circ}$ Encontro Perspectivas do Ensino de História, realizado na Universidade de São Paulo (USP), no período de 12 a 15 de fevereiro de 1996. Trata-se de uma versão modificada e reduzida do artigo "Livros Didáticos e Fontes de Informações sobre as Sociedades Indígenas no Brasil" (Silva, Grupioni, 1995).

${ }^{1}$ O grupo de trabalho foi instituído pela Portaría ${ }^{\circ} 1.130$, de 5 de agosto de 1993, assinada pelo ministro Murílio Hingel, e composto por membros indicados pelo Consed, Undime, Anped, SEF e FAE, divididos em quatro subgrupos: Português, Matemática, Ciências e Comunicação apresentada no grupo de trabalho "Textos Didáticos em Sala de Aula", no $2^{\circ}$ Encontro Perspectivas do Ensino de História, realizado na Universidade de São Paulo (USP), no período de 12 a 15 de fevereiro de 1996. Trata-se de uma versão modificada e reduzida do artigo "Livros Didáticos e Fontes de Informações sobre as Sociedades Indígenas no Brasil" (Silva, Grupioni, 1995).

${ }^{2}$ Refiro-me ao capítulo "Estudos Sociais" da publicação Definição de Critérios para a Avaliação dos Livros Didáticos: Iª 4"Série, editada pela FAE, em março de 1994. 
índio veiculado nestes manuais escolares? Em que momentos os índios aparecem na história do Brasil? De que forma são tratados?

Essas são algumas das questões que procurarei enfrentar aqui. Antes, todavia, gostaria de comentar um pouco mais o trabalho realizado pelo MEC. Além do Dia do índio, o Dia do Descobrimento do Brasil, da Bandeira e do Trabalho também aparecem citados em 51 livros, ficando atrás do Dia da Independência, que teve o maior número de citações: 59 livros. A lista de efemérides prossegue com datas curiosas, quer as observemos pela quantidade de livros em que aparecem, quer pelos inusitados critérios de pertinência provavelmente utilizados pelos autores desses manuais para darem destaques a elas: o Dia da Árvore é citado em 47 livros, o Dia do Soldado em 44, o Dia de Monteiro Lobato em 35 e o Dia Panamericano em 22. Com menos destaque, a Semana do Trânsito é citada em seis livros, o Dia das Aves em três e o Dia da Poesia em um.
Embora não caiba fazer aqui uma análise do que estas datas representam em termos de como os livros didáticos das primeiras séries estão organizados, "reforçando a mitificação de personagens e datas/marcos da política institucional", parece-me que elas são extremamente indicativas do que os avaliadores encontraram ao analisar os dez livros mais solicitados em 1991, para as primeiras séries escolares e que correspondem a cerca de $94 \%$ das aquisições realizadas pelo governo naquele ano. Não cabe aqui, também, fazer um resumo das conclusões deste grupo, mas é importante deixar o registro de que os livros didáticos continuam se mostrando deficientes, empobrecedores, generalizantes, muitas vezes desatualizados e marcados por erros conceituais, estereótipos e preconceitos.

O grupo de trabalho do MEC elegeu um conjunto de critérios e procedeu a uma análise dos livros mais solicitados em 1991. Em meio a esse quadro geral de deficiência do livro didático, os 
avaliadores perceberam o surgimento de algumas novidades e denunciaram em seu documento: "as mudanças são tópicas, superficiais e visam, na maioria das vezes, atrair o público consumidor, utilizando-se de estratégias muitas vezes enganosas.(...)" (FAE, 1994, p.69). Segundo, ainda, os avaliadores, "as obras analisadas não possibilitam que, ao final das quatro séries, os alunos se situem no espaço e no tempo em que vivemos, conheçam e analisem os aspectos básicos da realidade social brasileira, indispensáveis para a formação da cidadania. Além disso, nem despertam e nem preparam adequadamente os alunos para prosseguirem os estudos na área das Humanidades a partir da $5^{\mathrm{a}}$ série da escola fundamental" (FAE, 1994, p.66).

Pois bem. Tendo esse pano de fundo, proponho, aqui, retomar algumas análises de um tema pontual e apresentar uma reflexão sobre a forma pela qual os manuais didáticos usados na escola ajudam a formar uma visão equivocada e distorcida sobre os grupos indígenas brasileiros. Para tanto, empreenderei uma crítica aos livros didáticos em uso, apontando algumas de suas deficiências mais recorrentes.

$\mathrm{O}$ ponto de partida é que, apesar da produção e da acumulação de um conhecimento considerável sobre as sociedades indígenas brasileiras, tal conhecimento "ainda não logrou ultrapassar os muros da academia e o círculo restrito dos especialistas. Nas escolas, a questão das sociedades indígenas, freqüentemente ignorada nos programas curriculares, tem sido sistematicamente mal trabalhada. Dentro da sala de aula, os professores revelam-se mal informados sobre o assunto, e os livros didáticos, com poucas exceções, são deficientes no tratamento da diversidade étnica e cultural existente no Brasil (...). As organizações não-governamentais, que têm elaborado campanhas de apoio aos índios e produzido material informativo sobre eles, têm atingido uma parcela muito reduzida da sociedade" (Grupioni, 1992, p. 13). 
Assim, apesar da ampliação, nos últimos anos, do número daqueles que escrevem sobre os índios e de algumas tentativas de produção de materiais de divulgação, constatamos que o conhecimento produzido não tem tido o impacto que poderia ter: os índios continuam sendo pouco conhecidos, e muitos estereótipos sobre eles continuam sendo veiculados. A imagem de um índio genérico, estereotipado, que vive nu na mata, mora em ocas e tabas, cultua Tupã e Jaci e que fala tupi permanece predominante, tanto na escola como nos meios de comunicação.

Os próprios índios têm se dado conta desta situação e começam a reivindicar uma nova forma de relacionamento com o Estado e com segmentos da sociedade envolvente com os quais estão em contato. Nos encontros de professores indígenas, que têm acontecido em todo o território nacional, estes, além de discutirem a situação de suas escolas, têm também se pronunciado sobre este tema. No documento final do I
Encontro Estadual de Educação Indígena do Mato Grosso, realizado em maio de 1989 , os professores indígenas daquele estado registraram como uma de suas conclusões que "a sociedade envolvente deve ser educada no sentido de abolir a discriminação histórica manifestada constantemente nas suas relações com os povos indígenas." Os professores indígenas de Rondônia, também reunidos por ocasião de seu I Encontro em 1990, no documento que encaminharam aos Senadores da República, solicitaram a colaboração destes "para que se respeite os índios e suas culturas nas escolas não-indígenas e nos livros didáticos". Na Declaração de Princípios dos Povos Indígenas do Amazonas, Roraima e Acre, escrita em julho de 1991 pelos professores indígenas e reafirmada em outubro de 1994, é dado como princípio que "nas escolas dos não-índios, será corretamente tratada e veiculada a história e a cultura dos povos indígenas brasileiros, a fim de acabar com os preconceitos e o racismo". 
Sobre o livro didático

Sabemos da importância da escola, e do espaço ocupado pelo livro didático, no processo de formação dos referenciais básicos das crianças da nossa sociedade. A historiadora Norma Telles mostra que é na infância e na adolescência, portanto, durante o período em que se freqüenta a escola, que se recebe uma série de informações sobre outras culturas e sobre outros povos. Poucos terão, após essa fase, a oportunidade de aprofundar e de enriquecer seus conhecimentos sobre os outros, seja através de viagens, romances, mostras de filmes internacionais, seja prosseguindo seus estudos. Neste contexto, o livro didático é uma fonte importante, quando não a única, na formação da imagem que temos do Outro. Alie-se a isto o fato de o livro didático constituirse uma autoridade, tanto em sala de aula quanto no universo letrado do aluno. É o livro didático que mostra com textos e imagens como a sociedade chegou a ser o que é, como ela se constituiu e se transformou até chegar nos dias atuais (cf. Telles, 1987).

Cabe enfatizar que o livro didático é, muitas vezes, o único material impresso disponível para os alunos, cristalizando para ele, e também muitas vezes, por que não dizer, para o professor, parte do conhecimento a que eles têm acesso (cf. Pinto, Myazaki, 1985, p.165). Cabe, então, perguntar como o livro didático trata a temática indígena. Qual é a imagem do índio nos livros didáticos? Como o livro didático transmite informações sobre outras culturas e sobre outros povos?

Apresento, a seguir, as principais conclusões que historiadores, pedagogos e antropólogos chegaram em suas pesquisas. Para tanto, farei uso de algumas análises de materiais didáticos empreendidas por historiadores e antropólogos nos últimos anos, principalmente as conclusões de Rocha (1984), Pinto e Myazaki (1985), Almeida (1987) e Telles (1987). 
Os índios no livro didático: principais críticas

Um primeiro comentário se impõe: não é difícil encontrar nos livros didáticos afirmações, algumas vezes contundentes e fortes, contra o racismo e o preconceito e, portanto, encorajando os alunos a terem uma visão de "respeito e tolerância com relação aos grupos etnicamente diversos". Há, em quase todos, uma valorização de "uma nacionalidade que surge da diversidade". A congruência de três raças - brancos, negros e índios - na formação do povo brasileiro é sempre lembrada. Mas uma leitura mais atenta desses manuais mostra as dificuldades em lidar com a existência de diferenças étnicas e sociais na sociedade brasileira atual. O que normalmente fazem é recalcá-la para o passado (cf. Almeida, 1987, p.14).

Chega-se, assim, à primeira crítica ao livro didático: índios e negros são quase sempre enfocados no passado. Falar em índios é falar do passado, e fazêlo de uma forma secundária: o índio aparece em função do colonizador. Mas que passado é esse?

E aqui a segunda crítica: não se trata de uma história em progresso, que acumula e que transforma. É uma história estanque, marcada por eventos, eventos significativos de uma historiografia basicamente européia (cf. Telles, 1987).

Vejamos dois exemplos: poucos livros mencionam a questão da origem dos povos indígenas no continente americano. Para a maioria dos manuais, "a presença do 'índio' neste continente não é problematizada, é um fato consumado" (Pinto, Myazaki, 1985, p.170). Esses manuais privilegiam os feitos e a historiografia das potências européias, silenciando ou ignorando os feitos e a vivência dos povos que aqui viviam. Isto resulta no fato de o índio aparecer como coadjuvante na história e não como sujeito histórico, o que revela o viés etnocêntrico e 
estereotipado da historiografia em uso (cf. Telles, 1987).

Como entender, e aqui apresentamos o segundo exemplo, a data de 1492 ou 1500 como uma descoberta? O continente americano havia sido descoberto e habitado há milhares de anos atrás, quando as primeiras levas de homens saíram da Eurásia, passando pelo estreito de Bering e adentrando o continente americano pelo Norte. De lá, esses grupos migraram e ocuparam todo o continente. Assim, quando os europeus aqui chegaram, o continente americano vivia uma dinâmica própria, que foi substancialmente alterada com sua chegada. Mas não havia um mundo a ser criado ou à espera de seu descobridor. O conceito de descoberta só faz sentido se o entendermos dentro da perspectiva da historiografia européia. Como conceito, sua preocupação básica era o que ocorria na Europa, ignorando a história do continente americano (cf. Telles, 1987).

Ao desconsiderar a história do continente, os manuais didáticos erram pela omissão, redução e simplificação, ao não considerar como relevante todo o processo histórico em curso no continente. Chegamos, assim, a uma terceira crítica à forma como os livros didáticos tratam os índios: Como isto se dá?

Primeiramente, pela forma como essas sociedades são tratadas - geralmente pela negação de traços culturais considerados significativos: falta de escrita, falta de governo, falta de tecnologia para lidar com metais, nomadismo etc. Um segundo modo de operação deste mecanismo de simplificação é a apresentação isolada e descontextualizada de documentos históricos que falam sobre os índios. Assim, cartas, alvarás, relatos de cronistas e viajantes são fragmentados, recortados e, por que não dizer, adulterados e apresentados como evidências, como relatos do passado, sem que sejam fornecidos ao aluno instrumentos para que ele possa filtrar aquelas informações e reconhecê-las dentro do contexto 
no qual elas foram geradas. É assim que fatos etnográficos retirados do seu contexto, bem como iconografias da época, são apresentados, criando um quadro de exotismo, de detalhes incompreensíveis, de uma diferença impossível de ser compreendida e, portanto, aceita. E significativo, neste sentido, o fato de muitos livros didáticos usarem, basicamente, informações sobre os índios produzidas nos primeiros séculos da colonização, escritas por cronistas, viajantes e missionários europeus (cf. Rocha, 1984, p.29).

Isto pode levar os alunos a concluírem pela não-contemporaneidade dos índios, uma vez que estes são quase sempre apresentados no passado e pensados a partir do paradigma evolucionista, onde os índios estariam entre os representantes da origem da humanidade, numa escala temporal que colocava a sociedade européia no ápice do desenvolvimento humano e a "comunidade primitiva" em sua origem. Pode levar também a concluírem pela inferioridade dessas sociedades: a achar que a contribuição dos índios para nossa cultura resumir-se-ia a uma lista de vocábulos e à transmissão de algumas técnicas e conhecimentos da floresta.

Mas se é forte a apresentação dos índios no passado e como pertencentes a um tempo pretérito, fato é que a imagem do índio no livro didático não é una. Há diferentes imagens, contraditórias entre si, e fragmentadas. Assim como também são fragmentados os momentos históricos nos quais os índios aparecem. Os livros didáticos produzem a mágica de fazer aparecer e desaparecer os índios na história do Brasil. O que parece mais grave neste procedimento é que, ao jogar os índios no passado, os livros didáticos não preparam os alunos para entenderem a presença dos índios no presente e no futuro. $\mathrm{E}$ isto acontece, muito embora as crianças sejam cotidianamente bombardeadas pelos meios de comunicação com informações sobre os índios hoje. Deste modo, elas não são preparadas para 
enfrentar uma sociedade plurietnica, onde os índios, parte de nosso presente e também de nosso futuro, enfrentam problemas que são vivenciados por outras parcelas da sociedade brasileira (cf. Pinto, Myazaki, 1985).

Não obstante essa multiplicidade de imagens, é interessante notar a recorrência e a redundância de informações presentes nos livros didáticos: "Praticamente todos os livros informam coisas semelhantes e privilegiam os mesmos aspectos da sociedade tribal. Assim, todos os que lerem aqueles livros saberão que os índios fazem canoas, andam nus, gostam de se enfeitar e comem mandioca, mas, por outro lado, ninguém aprenderá nada sobre a complexidade de sua vida ritual, as relações entre esta e sua concepção do mundo ou da riqueza de seu sistema de parentesco e descendência" (Rocha, 1984, p.27).

Chegamos, assim, a mais uma crítica aos manuais didáticos: eles operam com a noção de índio genérico, ignorando a diversidade que sempre existiu nessas sociedades. Eles são "tratados como se formassem um todo homogêneo e como se a generalização fosse a maneira correta de estudá-los" (Rocha, 1984, p.32). É evidente que as sociedades indígenas compartilham um conjunto de características comuns e que são estas características que as diferenciam da nossa sociedade e de outros tipos de sociedades. Mas as sociedades indígenas são extremamente diversificadas entre si: cada uma tem uma lógica própria e uma história específica, habitam diversas áreas ecológicas e experimentaram situações particulares de contato e troca com outros grupos humanos. Têm, portanto, identidades próprias: "cada sociedade indígena se pensa e se vê como um todo homogêneo e coerente e procura manter suas especificidades, apesar dos efeitos destrutivos do contato. Um Guarani ou um Yanomami, apesar de índios, vão continuar se pensando como um Guarani e como um Yanomami" (Grupioni, 
1992, p. 18). Essa verdade - a de uma rica diversidade sociocultural indígena - não aparece nos livros didáticos.

\section{O índio na história do Brasil, segundo os livros didáticos}

Voltemos às imagens contraditórias e fragmentadas, manipuladas pelos livros didáticos, para dar conta da presença do índio na nossa história (cf. Almeida, 1987, p.40-70). Recapitulemos, ainda que rapidamente, essas principais imagens.

Num primeiro momento da nossa história, que, de acordo com os livros didáticos, começa com a chegada dos europeus, os índios da colônia são cordiais e amigáveis: carregam o pau-brasil em troca de bugigangas e miçangas, ajudam os portugueses a construir fortes e casas que dão origem às primeiras povoações e ensinam os brancos a sobreviver e a conhecer a nova terra.

Logo em seguida, entretanto, os índios começam a atrapalhar a colonização. São os Tamoios que se aliam aos franceses e promovem ataques aos núcleos dos brancos. O brasileiro é o português neste momento, os franceses são estrangeiros e os índios os aliados, ora do estrangeiro, ora do brasileiro (cf. Almeida, 1987, p.45). De cordiais, os índios passam a ser traiçoeiros. A colonização exige, por sua vez, trabalho, e o índio é mãode-obra utilizada em toda a colônia. Nesse momento, a figura do índio aparece ligada à do bandeirante, que expande o território e resolve o problema da mão-de-obra, escravizando índios e depois recapturando negros fugidos (Almeida, 1987, p.47). Mas a escravidão negra só se inicia porque, como explicam vários manuais, o índio não era afeto ao trabalho: "eram preguiçosos" e sua índole para a liberdade não permitia que ele vivesse sob o jugo da escravidão. É nesse momento também que apareceu a figura do índio que deve ser "civilizado", ou melhor, "catequizado". Não são poucas as figuras que trazem 
Anchieta e Nóbrega com indiozinhos aos seus lados.

Mas, depois disto, o índio desaparece, não antes de nos legar algumas generalidades: são Tupis, adoram Jaci e Tupã e moram em ocas e tabas. E também uma herança: ensinam algumas técnicas, como a queimada, a fabricação de redes e esteiras e nos deixam suas lendas. Eles viram uma herança cultural a ser resgatada pela nacionalidade (cf. Almeida, 1987, p.64-65). Tempos depois, ao se falar da necessidade de ocupação dos espaços vazios, não se fala mais de índios. E como se o território do Centro-Oeste e do Norte do Brasil fosse virgem, como se ninguém morasse por lá (cf. Almeida, 1987, p.37-40; Telles, 1987, p.76-82).

E é assim que chegamos aos índios atuais, isto quando chegamos, pois a maior parte dos livros didáticos não aborda a presença indígena no presente. Pulverizam-se dados, muitas vezes incorretos. Falam da existência de índios na Amazônia e no Xingu, lembram dos trabalhos de Rondon e dos Vilas-Boas e referem-se à Funai.

\section{Bons e maus selvagens: imagens contraditórias e fragmentadas}

Presentes em muitos manuais didáticos, essas imagens diversas e contraditórias dos índios parecem encobrir uma dicotomia que perpassa toda a história: ou há índios vivendo isolados na Amazônia e protegidos no Xingu ou já estão contaminados pela civilização e a aculturação é seu caminho sem volta. Esta dicotomia pode ser descrita de outra forma: ou estão no passado ou vão desaparecer em breve. Estas soluções apresentadas pelo livro didático nos remetem a duas perspectivas opostas e a eles sempre associadas: a do bom e a do mau selvagem. Sua origem talvez possa ser buscada nos primeiros anos do contato dos europeus com as populações do Novo Mundo, quando do célebre debate ocorrido em 1550 entre o dominicano Las Casas e o jurista Sepúlveda, ou nas proposições filosóficas do século XVII, representadas por Rousseau e Hobbes, o primeiro argumentando que os índios representariam um estágio primitivo da 
humanidade, vivendo basicamente pelos seus instintos, e o segundo propagando a teoria da degenerescência, onde os índios viveriam num passado, numa era sem ordem, e que só a civilização os levaria para o progresso.

Born e mau selvagem são imagens opostas e parecem catalizar o imaginário sobre os índios na nossa sociedade. Imagens cristalizadas ao longo de séculos, elas parecem, hoje, revelar algo de concreto e diante delas não se pode ficar indiferente: ou os índios são bons e é preciso que os protejamos tais como eles são, ou os índios são maus e é preciso trazê-los logo à "civilização". Um antropólogo francês revela que tais imagens tomam o homem civilizado como parâmetro para comparação. De um lado, há a figura do bom selvagem e do mau civilizado, que espelha uma fascinação pelo estranho e pela pureza, com valores e ideais a serem resgatados, e, de outro, a figura do mau selvagem e do bom civilizado, marcando uma recusa do estranho, visto como um empecilho ao progresso da humanidade (cf. Laplantine, 1988).
São imagens fortes, as quais, todavia, não devemos tomar de forma tão polarizada ou monolítica, sob o risco de perder as nuances que elas efetivamente carregam. Neste sentido, os livros didáticos são criativos em mesclar tantas figuras diferentes e contraditórias, dando uma sensação de unicidade. Feita a ressalva, devemos reconhecer que estas duas imagens nos permitem uma aproximação da forma como a sociedade ocidental representa tais sociedades: contraditórias entre si, elas realizam uma simplificação da questão e demonstram a nossa incapacidade em compreender um outro, que é diferente, em seus próprios termos.

É assim que a questão indígena tem estado envolta num ambiente de preconceito, intolerância e muita desinformação.

A solução apresentada por vários livros didáticos parece ser a de que, na história do Brasil, esse índio bom contribuiu para a colonização e deixou traços culturais para a nossa nacionalidade. Mas esse índio acabou por desaparecer. Já o índio mau, o índio problema, esse é o 
que ainda ocupa espaços e que atrapalha o desenvolvimento (cf. Almeida, 1987, p.69-70).

Enfim, a conclusão geral que podemos tirar disto tudo é que os manuais escolares continuam a ignorar as pesquisas feitas pela história e pela antropologia no conhecimento do Outro, revelando-se deficientes no tratamento da diversidade étnica e cultural existente no Brasil, dos tempos da colonização aos dias atuais, e da viabilidade de outras ordens sociais. E é com esse material, equivocado e deficiente, que professores e alunos têm encontrado os índios na sala de aula. Preconceito, desinformação e intolerância são resultados mais que esperados deste quadro.

\section{Para reverter a situação: algumas idéias}

Para reduzir ou acabar com o preconceito e a discriminação, é preciso gerar idéias e atitudes novas, num processo que deve ser levado tanto em nível individual como coletivo. Isso se faz com informações corretas e contextualizadas, que levem as pessoas a refletir sobre suas posturas e atitudes cotidianas. ${ }^{3} \mathrm{Se}$ levarmos em conta que atitudes preconceituosas implicam em apreciações feitas sem um conjunto de informações satisfatórias, é lógico esperar que, melhorando a informação, o sultado sejam mudanças de atitude (cf. Klineberg, 1976, p.427). Por outro lado, a explicitação dos mecanismos de preconceito $\mathbf{e}$ discriminação deve nos levar a analisar não somente nossas atitudes e idéias individuais, mas também nossas práticas coletivas de discriminação, de concordância e de convivência com posturas discriminatórias e preconceituosas presentes no nosso dia-adia.

Os livros didáticos são deficientes no tratamento da diversidade étnica existente no

${ }^{3}$ Uma experiência interessante de combate à discriminação foi a criação, no âmbito da Secretaria de Estado da Educação de São Paulo, de uma Comissão contra a Discriminação, que desenvolveu programas junto às escolas públicas do Estado de São Paulo. Essa comissão elaborou a cartilha A Escola na Luta contra a Discriminação, 1987. 
Brasil, tanto em termos históricos como atuais: um conjunto de informações incorretas, incompletas ou descontextualizadas sobre os indios acaba gerando ou reforçando o preconceito e a discriminação. Cabe, agora, perguntarmos como é possível reverter esta situação. Como é possível a escola, que desempenha um papel fundamental na formação do nosso referencial explicativo da realidade, colaborar na construção de uma sociedade plurietnica, capaz de respeitar e conviver com diferentes normas e valores?

O caminho é rever conhecimentos, perceber deficiências, buscar novas formas e novas fontes de saber. O professor precisa levar para dentro da sala de aula a crítica séria e competente dos livros didáticos e o exercício de convívio na diferença, não só entre membros de sociedades diferentes, mas também entre aqueles que têm origens regionais e culturais diversas. Por sua vez, o professor tem hoje à sua disposição uma produção "paradidática" recente e de boa qualidade, que pode auxiliá-lo na tentativa de tratar a questão indígena em sala de aula de forma contextualizada e livre dos estereótipos presentes nos manuais didáticos tradicionais. Ele pode contar, também, com o apoio e a assessoria de grupos de pesquisas existentes em diferentes universidades brasileiras, bem como de organizações nãogovernamentais de apoio aos índios, que vêm desenvolvendo trabalhos de difusão e informação sobre a questão indígena. ${ }^{4}$ Os antropólogos, que por força de profissão mantêm contatos intensos com os grupos indígenas e estudam a questão da diversidade, precisam tomar para si e como um desafio a tarefa de produzir materiais adequados e contextualizados para um público mais amplo que aquele dos especialistas. ${ }^{5}$ Os autores destes

\footnotetext{
${ }^{4}$ Merece destaque, neste sentido, o trabalho que vem sendo desenvolvido pela Associação Nacional de Apoio aos índios da Bahia (Anaí-BA), junto aos professores da rede pública da cidade de Salvador.

${ }^{5}$ Cito aqui a recente publicação A Temática Indigena na Escola: Novos Subsídios para Professores de $1^{\circ}$ e $2^{\circ}$ Graus, organizada por Aracy Lopes da Silva e Luis Donisete Benzi, que envolveu a participação de mais de 40 especialistas na produção de textos e artigos sôbre as sociedades indígenas no Brasil, e que obteve o apoio do MEC e da Unesco para sua edição.
} 
manuais didáticos precisam rever suas fontes e as teorias que seguem, balizando seus livros em pesquisas mais contemporâneas. As editoras, por sua vez, precisam ser mais cuidadosas no controle dos materiais que publicam. E o governo federal deve incentivar avaliações sistemáticas dos livros didáticos beneficiados nos programas de compra e distribuição de material didático para todo o País. Por fim, cabe aos próprios índios - e muitos representantes indígenas já estão em condições de manter um diálogo mais efetivo com a sociedade nacional - "pacificar" e "civilizar" os não-índios.

Referências bibliográficas

ALMEIDA, Mauro William Barbosa de. O racismo nos livros didáticos. In: SILVA, Aracy Lopes da (Org.). A questão indígena na sala de aula: subsídios para professores de $1^{\circ}$ e $2^{\circ}$ graus. São Paulo: Brasiliense, 1987. 253p.il. p.13-71.
FDE. Comissão Contra a Discriminação. A escola na luta contra a discriminação. São Paulo: FDE, 1987. (sic).

FUNDAÇÃO DE ASSISTÊN-
CIA AO ESTUDANTE. Estudos Sociais. In:

Definição de critérios para avaliação dos livros didáticos: $1^{\mathrm{a}}$ a $4^{\mathrm{a}}$ série. Brasília: Ministério da Educação, 1994. $4 \mathrm{v}$.

GRUPIONI, Luis Donisete Benzi. As sociedades indígenas no Brasil através de uma exposição integrada. In: . (Org.). índios no Brasil. São Paulo: Secretaria Municipal de Cultura, 1992. 279p.p. 13-28.

KLINEBERG, Otto. Prejuicio. In: SILLS, David L. Enciclopédia internacional de Ias ciências sociales. Madrid: Aguilar, 1976. V.8. p.422-429.

LAPLANTINE, F. Aprender antropologia. São Paulo: Brasiliense, 1988.

PINTO, Regina Pahim, MYAZAKl, Nobue. A representação do 
índio nos livros didáticos na área de Estudos Sociais. Revista do Museu Paulista, São Paulo, V.30, p.165-191, 1985.

ROCHA, Everardo Pereira Guimarães. Um índio didático: nota para o estudo de representações. In: ROCHA, Everardo Pereira Guimarães et al. Testemunha ocular: textos de antropologia social do cotidiano. São Paulo: Brasiliense, 1984.
SILVA, Aracy Lopes da, GRUPIONI, Luis Donisete Benzi (Org.). A temática indígena na escola: novos subsídios para professores de $1^{\circ}$ e $2^{\circ}$ graus. Brasília: MEC, 1995. 575p.

TELLES, Norma. A imagem do índio no livro didático: equivocada, enganadora. In: SILVA, Aracy Lopes da (Org.). A questão indígena na sala de aula: subsídios para professores de $1^{\circ}$ e $2^{\circ}$ graus. São Paulo: Brasiliense, 1987. 